\title{
Compliance with the Requirements of the Environmental Impact Assessment Guidelines in Zimbabwe: A Case Study
}

\author{
Rowan Kushinga Machaka ${ }^{1}$, Lakshmanan Ganesh ${ }^{1} \&$ James Mapfumo $^{2}$ \\ ${ }^{1}$ Centre for Research, Christ University, Bangalore, India \\ ${ }^{2}$ Christ College, Harare, Zimbabwe \\ Correspondence: Rowan Kushinga Machaka, Centre for Research, Christ University, Bangalore India. Tel: \\ 61-040-682-2131. E-mail: kushinga.machaka@res.christuniversity.in
}

\author{
Received: August 1, 2016 Accepted: August 24, 2016 Online Published: September 27, 2016 \\ doi:10.5539/jsd.v9n5p121 URL: http://dx.doi.org/10.5539/jsd.v9n5p121
}

\begin{abstract}
This research set out to find out how well projects are complying with the requirements of the Environmental Impact Assessment Guidelines in Zimbabwe. Data was collected from EIA reports completed between 2007 and 2012. Questionnaires and interviews were used to collect the experiences of practitioners in the EIA sector. The results show that EIA reports contain below $65 \%$ of required information for decision making. Critical sections of the EIA report are the most deficient. Compliance varies significantly between consultants, stage of EIA process and size of project. Recommendations are: need to review and expand the existing guidelines and promote their use, building objectivity into the EIA report review process, upholding professional standards of practice for the consultants, improvement of compliance monitoring and enforcement, the use of economic incentives and disincentives other than enforcement to promote compliance, increased awareness raising of EIA in the business sector, and increased political will and transparency.
\end{abstract}

Keywords: environmental impact assessment (eia), environmental compliance, environmental assessment, environmental policy

\section{Introduction}

Like most African countries, Zimbabwe initiated the process of environmental impact assessment (EIA) policy formulation in response to the Rio Local Agenda 21 Declaration (1992) resulting in the policy being codified in 1994 (Ministry of Environment and Tourism, 1997). In 1997, EIA Guidelines were published and operationalised to guide EIA practitioners and stakeholders in the process of carrying out EIA studies. Although it was not law then, the EIA policy set out the parameters that needed to be followed by those who opted to subject their development initiatives to the EIA policy. Funding agents, donors as well as local banks played a role in the adoption of EIA practice by demanding compliance with EIA requirements before committing resources to projects. As a result, the EIA policy was widely implemented in all sectors of the society even before it was law.

In 2003, the EIA policy was incorporated into law within the Environmental Management Act (Chapter 20.27) thereby giving the regulating authority more powers to regulate the application of the EIA system. Zimbabwe is one of the countries with well documented step-by-step guidelines for carrying out EIA studies and implementing environmental management plans. The stated purpose of the EIA Guidelines (1997) is "to facilitate compliance with the EIA policy by government departments, project developers and the general public".

In short, the EIA Guidelines require that a study of a project's anticipated impacts be done. Thereafter, mitigation measures are formulated to reduce or avoid the anticipated impacts. The result of the study is an EIA report which is submitted to the relevant authority for approval/acceptance.

The proponent (or developer) has the responsibility to conduct an EIA study. To do so, the proponent engages a consultant who has competency to conduct the EIA study and produce a report.

The EIA process can be split into pre-certification and post-certification stages. The main steps of the EIA Guidelines are:

(1) Screening - to determine if a full EIA study is required; 
(2) Prospectus - a document produced by the proponent informing the regulatory authority about the main environmental issues of the project which need to be considered during the EIA Study:

(3) Terms of Reference (TOR) and Scoping - specify how the EIA study is to be conducted;

(4) EIA Study - a scientific process of studying the baseline, the impacts and formulating the mitigation measures which culminates in the EIA report which contains the environmental management plan (EMP);

(5) EIA Report Review - decision point by the regulatory authority whether to allow the project to be implemented or not (acceptance);

(6) Terms and Conditions - if project is given acceptance, additional conditions can be included for implementation by the proponent; and,

(7) EMP implementation and Monitoring and Auditing - execution of the mitigation measure including monitoring to ensure that the EMP is being implemented according plan and that any emergent impacts/ issues are addressed.

Therefore, the EIA Guidelines stipulate the content which is required in each of the sections of the EIA Report.

\subsection{The Problem}

The EIA system is based on the precautionary principle, which requires action to be taken to avert anticipated environmental problems even without scientific certainty that the problems will occur. It is a system of anticipating negative impacts to the environment and avoiding or mitigating them. For this reason, a series of EIA process steps were designed to ensure that environmental impacts are incorporated into economic projects. Compliance with these steps is crucial to ensure that the EIA system is on track. If compliance is lacking, there is no basis to expect that the environment is being protected as required by law.

In addition, establishing and administering the EIA system demands large quantities of resources for all the stakeholders involved. Hence, it is important to review the level of compliance in order to justify the amount of resources committed to EIA systems.

This study fills in the need to assess compliance issues surrounding implementation of the EIA system in Zimbabwe and draw out lessons to feed into relevant policies. This study will attempt to evaluate how projects are complying with the requirements of the EIA system.

\subsection{Literature Review}

The importance of compliance to the effectiveness of EIA system as noted by several authors since long ago (Wasserman, 1992; Benson et al, 2006, cited in Kahangiwre (2011)). It is not surprising that much research has been conducted on this theme. Compliance is thus critical to effective EIA systems.

Some studies on EIA compliance have been carried out in Africa. In Uganda, Manyindo (2002) found that compliance and impact management are neglected while there is a misconception that the EIA process is done to obtain a certificate. In Malawi, Mhango (2005, p. 389) found out that $93.75 \%$ of the EIA reports had less than $50 \%$ compliance grade. This inadequacy was attributed to capacity issues and to lack of mandatory guidelines. Mhango (2005) also found out that other than screening and impact analysis, other requirements of EIA reports are poorly adhered to.

Betey and Godfred (2013:45) reviewed the EIA systems of four African countries (Egypt, Ghana, Mauritius and South Africa) and found out that monitoring of post-certification compliance was generally lacking except where there are complaints or disasters.

Outside Africa, in Pakistan, Nadeem and Hameed (2006) attributed poor EIA practice to proponent's attitudes, lack of consultants' experience, inconsistent EIA review criteria, and inadequate expertise for the review of EIA reports. In a case study of post-certification compliance monitoring using specific parameters in Nepal, Khadka and Khanal (2008, p. 93) found that monitoring was sometimes as low as $23 \%$. They noted that compliance improved to $90 \%$ due to the following reasons: appointment of qualified personnel, training of personnel and imposed penalty for non-compliance.

Therefore, it appears that there is a general trend of inadequate compliance in different country, albeit for differing reasons.

EIA evaluation studies tend to measure effectiveness from a procedural point of view (Cashmore et al, 2004; Pope et al, 2013). This focusses on how the EIA system is being implemented other than what has been achieved. This study is no exception. 


\subsection{Delineation}

This Section describes the constructs used in this study.

The EIA system is defined as the sum total of institutions, processes, resources and relationships which form the mechanism for implementing the EIA policy or law.

The EIA process is a series of steps that are stipulated in the EIA policy or law and especially the guidelines through which the EIA policy or law is implemented.

The compliance with the EIA system is defined as the average proportion of the EIA system steps that are complied with by all projects. The other part of the variable is the degree to which the proponents adhere to the steps of the system, i.e. is the compliance being carried out to the extent expected. Therefore, when a proponent produces for example, an environmental management plan, the proponent has complied with the requirement. However, the environmental management plan may not be of the expected quality, which is the quality of compliance. The quality of the compliance is difficult to measure based on the EIA report alone without verification on the location of the project and the implementation. Therefore, this study focused on simply establishing whether the particular step of the EIA system has been complied with regardless of how well.

The goal of this research is to evaluate compliance of new projects with the requirements of the EIA system in Zimbabwe.

\subsection{Objectives of the Study}

The specific objectives are:

i. To measure the proportion of the EIA Guideline requirements that are complied with;

ii. To find out difference in compliance with respect to consultants, project size, project type (economic sector), annual trend between 2007-2012, and, the stage of the EIA process;

iii. To understand the factors affecting compliance by proponents; and,

iv. To find out the major factors affecting compliance with EIA Guideline requirements.

\subsection{Hypothesis}

The hypotheses of the study are as follows:

i. There is no difference in observed and expected compliance of EIA reports at $65 \%$;

ii. There is no correlation between compliance of EIA reports and years 2007 to 2012;

iii. There is no difference in compliance of EIA reports between economic sectors;

iv. There is no difference in compliance between small and large projects;

The first hypothesis relates to the first objective, whilst the second, third and fourth hypotheses relate to the second objectives. There are no hypotheses for objectives three and four which pertain to interview data.

\section{Method}

\subsection{Study Design}

The study was designed as a process evaluation approach which measured the process which is being used to attain desired results of the environmental impact assessment legislation and policy against the requirements. Being a mixed method design also entailed the use of both quantitative methods for questionnaires and secondary data and qualitative methods for interview data.

The study was designed as a survey using both qualitative and quantitative techniques. Three tools were used to collect data. Secondary data was collected through enumeration using a checklist. The enumeration involved identifying if the required content was available under the relevant sections of the EIA reports. EIA reports obtained from willing consultants were reviewed and the checklist form was completed for each of the 65 EIA reports made available.

\subsection{Sampling}

Three sources of data were used. For EIA reports (secondary data), ten willing consultants provided the research with sixty-five EIA reports. Therefore, convenience sampling was used to obtain a sample size of 10 consultants from a population of about 60 consultants.

For questionnaires, the population was made up of all consultants and individuals with knowledge of EIA in Zimbabwe who could be reached through online professional websites or email. A total of 578 questionnaires 
were conveniently administered by email using online survey software. Seventy-five responses were received, of which 66 were considered valid for analysis.

Fifteen individuals known to have been involved in the EIA system for more than 10 years were specifically targeted in a purposive sampling. The reason was that the interviews were necessary to give deeper insights which explain the current observed status of the EIA system especially the historical trends that have shaped the EIA system in Zimbabwe.

Primary data was collected in two ways. Firstly, a questionnaire was designed with a Likert scale of 1 to 5 (strongly disagree, disagree, average/neutral, agree and strongly agree) with constructs that measure experiences of respondents with respect to EIA compliance.

Secondly, interviews were conducted with experts to delve into the deeper underlying factors of the EIA systems. Interview discussions involved the three research open-ended questions followed by circumstantial follow-up questions where necessary. The split-half method using the Cronbach's alpha was used to assess the saturation point of the sample of questionnaires.

\subsection{Limitations}

Some limitations of the study are as follows. The study was clearly limited by the feasibility of obtaining data pertaining to certain elements of the EIA system. Only those consultants confident of their work were willing to submit their reports hence the actual compliance may be much worse or better than measured by this study. However, the study provides a reasonable snapshot. Therefore, from a statistical point of view, the generalizability of the findings of this study is limited.

The enumeration process used to collect data from EIA Reports only checked the presence of required content in the sections of the EIA reports. The quality of the content was not assessed due to the verification difficulties.

\subsection{Data Analysis}

The choice of statistical tools was dictated by the need to compare the observed against the expected. Hence, comparison of means, correlation and test of association were used to analyse the data and to test the different hypotheses. Interview data was grouped according to themes using the thematic analysis approach.

\section{Results}

This section will present the results according to the research objectives.

\subsection{To Measure the Proportion of the EIA Guideline Requirements That Are Complied with}

Chi-square analysis of secondary data showed that there is a difference $(\mathrm{p}=0.05)$ between observed compliance $(59 \%)$ and expected compliance of $65 \%$ with the EIA reports alone.

Chi-square analysis of the questionnaire data showed that there is a significant difference $(p=0.05)$ between observed compliance and expected compliance of 50\%.

3.2 To Find out Compliance with Respect to Consultants, Project Size, Project Type (Economic Sector), Annual Trend between 2007-2102, and, the Stage of the EIA Process

Analysis of variance showed that there is significant difference $(\mathrm{p}=0.05)$ between compliance of consultants in EIA reports. Pearson's correlation analysis showed that there is correlation $(\mathrm{p}=0.05)$ between compliance and year of EIA reports. Analysis shows a moderate positive correlation $(0.331)$ which means that EIA Report compliance has moderately improved from 2007 to 2012;

Analysis of variance also showed that there is no significant difference $(p=0.05)$ in compliance between economic sectors of EIA reports. The Mann-Whitney U-test was used to analyse compliance between large and small projects, and compliance between pre and post-acceptance. The results show that there is significant difference $(\mathrm{p}=0.05)$ in compliance between large and small projects, and in compliance between pre and post-acceptance.

\subsection{To Understand the Factors Affect Compliance by Proponents}

The questionnaires were used to measure the factors that explain why proponents may fail to comply. Six factors were identified as follows (in order of increasing importance): (i) the EIA system is unclear (3.42), (ii) EIA is unnecessary (3.28), (iii) EIA is too stringent (2.61), (iv) EIA is too expensive (2.60), (v) EIA increases costs (2.16), and (vi) EIA delays projects (2.14).

\section{Discussion}

Results show that EIA reports comply with less than $65 \%$ of EIA Guideline requirements and that the contents of 
EIA reports vary widely. It implies that on the average the decision-makers have less than $65 \%$ of required information to make their decision. Considering that the EIA system is based on the precautionary principle where uncertainty is high, there is need to have as much information as possible to make the most accurate choices. EMA reported that $31.7 \%$ of EIA reports do not meet standard (EMA 2011:8).

The difference in compliance between sections of the EIA reports was also assessed. Some of the reports lack critical information necessary for decision-making, successful implementation of mitigation measures and future evaluation of the impact of the project on the environment. The most lacking sections of the EIA are also the most crucial. These are impact analysis, EMP, participation, alternative analysis, EMP and pre-design. Pre-design refers to those voluntary environmental aspects/measures that the proponents build into the project before an EIA study is done.

Without impact analysis it is not possible to accurately predict the impacts and without an elaborate and costed EMP the implementation of mitigation measures is likely to fail. Without adequate participation of stakeholders, the EIA decision misses some relevant information and even impinges on stakeholders' rights. Without adequate alternative analysis the EIA report lacks information on the most feasible and environmentally suitable options. Lack of pre-design shows a disregard of environmental issues from the beginning of the project.

The wide variance in EIA reports' content also suggests that the methods being used to conduct EIA studies are widely different. Interview results shows that it is not standard practice for consultants to refer to the EIA Guidelines when conducting EIA studies or producing the EIA reports. Instead, consultants use previously approved EIA reports as template on which to base future EIA reports.

The results also show that the consultants do not produce EIA reports of comparable quality (standard deviation $=12.49 \%$; Range $=56.08 \%$; Mean 59\%). A number of observations raised by interview respondents can explain this discrepancy. Firstly, this maybe a result of the differences in competency levels between the consultants registered by EMA to provide EIA consultancy services. Some registered consultants simply do not have the competency. This reflects on the appropriateness of the vetting system used to screen consultants before they are registered as well as the capacity building that consultants are exposed to before they can be deemed competent enough to conduct EIAs. The impact analysis, alternative analysis and mitigation are especially technical parts of the EIA reports which demand higher competency levels.

Secondly, it has also been observed that EIA studies are sometimes conducted by non-registered consultants even though the EIA reports are submitted under the names of registered companies. Therefore the consultants who are certified to be competent are not necessarily using their competency to produce the EIA reports.

Thirdly, this is also due to the differing levels of effort that the consultants exert depending on how much they are paid for the job. It has also been observed that some consultants charge fees which are too low for a thorough EIA study, hence the quality of the work reflects how much they are being paid. In some instances, in order to reduce costs, consultants constitute smaller teams than required to conduct a proper EIA.

Lastly, the consultants face difficulties in obtaining necessary information for baseline studies resulting in such information being excluded from the report.

The finding that compliance of EIA reports has improved moderately since 2007 is positive for the EIA system and implies that both EMA and consultants have been addressing some of the compliance gaps in the production of EIA reports.

It is somewhat surprising that there is no difference between compliance of economic sectors in the EIA reports. Respondents to questionnaires and interviews tended to think that some economic sectors are more compliant than others. However, given the fact that EIA study guidelines are almost generic across all projects regardless of sector, it is not surprising that there is no difference between EIA report compliance between sectors. If guidelines demanded more stringent sector specific requirements in carrying out EIA studies, the results would be different.

The findings also show that large projects have a higher level of compliance than the smaller projects. Both questionnaire and interview respondents make the same observations. The reason is that large projects often have adequate budgets to hire internal staff responsible for environmental issues. Large projects are also more conspicuous therefore their environmental impacts will attract more attention. Therefore, it is in the interest of a large project to be compliant with all environmental requirements.

This study included assessing if respondents felt that the different stages of the EIA system are complied with differently i.e. the pre-acceptance versus the post-acceptance stages. Compliance of the pre-acceptance stage was rated higher than the post-acceptance stage comprising of the EMP and the quarterly reporting. Therefore there is 
a general tendency to comply with the pre-acceptance stage better than the post acceptance stage of the EIA process. EMA "monitoring reveals that most proponents were not implementing the provisions of their own EMPs as specified in EIA reports" (EMA 2011:10). The EMA report further states that due to compliance failure "1475 tickets and 169 closure orders were issued of which $80 \%$ of offenders paid fines while $20 \%$ are pending court cases". This finding agrees with this EMA report and findings of other writers (Kahangirwe, 2011).

Proponents are primarily worried about the costs associated with delays in project implementation and complying with EIA regulations. The period from the time of contracting the consultant until an EIA certificate is granted can last anything from 3 months to more than 6 months of which stakeholder consultations and report review accounts for most of the time. Wood (2003:7) noted that in developing countries "there is probably a majority view" that EIA benefits are not commensurate with the time and costs. This study confirms that view but project delays are a major concern.

Corruption was decidedly the lowest scored of all the ratings in this study (1.94 out of 5) showing that most of the respondents agree that corruption is a serious issue affecting compliance in the EIA system.

\subsection{Factors Affecting Compliance with EIA Guideline Requirements}

A decision criteria template (EIA Report review criteria) was obtained from the regulatory authority and interviews were held with key informants to answer this question. The analysis showed that there is limited objectivity in reviewing EIA reports since the EIA Report review template has no objective empirical measure of compliance or adequacy of the EIA report content but is based in general subjective impressions of the reviewer. Whilst other government departments are expected to be involved in reviewing EIA reports which touch on their mandates, in practice this is not easy because they are focused on their own work. Hence the review often reflects the viewpoints of EMA alone.

Site visits are carried out by EMA personnel sometimes including other government departments as part of the review of the EIA report to inform EIA certificate decision. However, there is lack of adequate equipment to measure and monitor some environmental indicators such as ambient air quality. Such measurements are necessary to verify claims made in the EIA reports.

Interviewees noted that there is no clear relationship between the EIA Report review template and the EIA Guidelines. Hence the guidelines used to formulate report are, to some extent, different from the template against which compliance is assessed. The discretion of EMA staff performing the review is a major factor to the decision to grant acceptance or not.

Thematically, the major challenges to compliance that were identified through the interviews are:

- Inadequate enforcement of EIA requirements especially EIA report quality, implementation of mitigation measures and impact monitoring.

- Lack of specialisation in EIA, low entry barriers, unethical practices by consultants and inadequate consultant vetting methods resulting in EIA services being provided by incompetent consultants even though the competent ones are available.

- Lack of up-to-date EIA guidelines to facilitate EIA studies that are scientific which can provide adequate decision-making information.

- Lack of baseline information for EIA studies due to inaccessibility of existing information within the regulatory authority's possession as well as inadequate time and equipment for measuring baseline parameters.

- Delays caused by EIA reports which do not meet the regulator's standards necessitating submission and re-submission(s) of the same EIA reports for review before the quality of the EIA report meets approval requirements.

- Lack of awareness of EIA requirements as well as general low priority given to environmental issues by proponents.

- An EIA report review checklist which depend on reviewer's subjective impression and is not properly synchronized with the EIA report requirements in use by consultants resulting in confusion of exactly what an EIA report should carry, hence continually changing but uncommunicated EIA report requirements.

- Various forms of corrupt practices within the EIA system especially between and within the regulator, consultants and proponents. 


\section{Conclusion}

In conclusion, the findings show that although compliance in the EIA system in Zimbabwe improved slightly between 2007 and 2012, it was still inadequate in EIA reports and is below average expectations of EIA practitioners. The EIA Guidelines are not adequately complied with. The EIA system is therefore not effectively achieving its intended objective of incorporating environmental concerns into project planning. The implementation of mitigation measures stipulated in the EMPs is least complied with.

The implication is that the EIA system is not effectively achieving its intended objectives since strict compliance is necessary to achieve the protection of the environment.

\section{Recommendations}

Many recommendations can be suggested based on the findings. However, some key recommendations are as follows.

Since only $65 \%$ of the guidelines are complied with, there is need for emphasis on the EIA guidelines for carrying out EIA studies so that the EIA report quality can be improved and standardised. In addition, since many adjustments have been made by EMA to the process of carrying of EIA studies, it is prudent to produce an update version of the guidelines which reflect current EMA requirements.

The EIA review checklist/template used by EMA requires objectivity to be built into it. There is need to work out a template which contains empirical and objective measures of EIA report content. In addition, the EIA review checklist must be synchronised with the EIA guidelines to ensure that EIA reports are produced according to the format by which they will also be reviewed against. This will provide a common traceable standard of EIA report quality for both EMA and consultant. Literature contains various EIA Report review templates and models from which the EIA system can build its own.

Consultants play a key role in enhancing compliance in the EIA system. Since most consultants are professionals in their own fields without specific EIA skills and they are not fulltime on EIA studies, there is need to ensure that consulting companies have within their teams the capacity to meet EIA competency requirements. Some respondents recommended that, in addition to providing more regular training, EMA should also give performance feedback to consulting companies as well as promote specific specimen of EIA report best practices within EMA's library for reference.

Related to the foregoing point is the observation that the EIA system has gathered much information since 1997 which is stored but unavailable to experts who need it for use in EIA studies. The main hurdle is the Environmental Management Act (CAP 20.27) Section 108 which seems to forbid personal use of EIA reports outside "civil proceedings ... in a matter relating to the protection and management of the environment". This situation is uniquely Zimbabwean since in many countries EIA reports are publicly available without restriction and many can be downloaded online. This situation casts a cover over transparency in the EIA system.

Awareness building among proponents is an ongoing process which EMA has pursued with some success. However, because proponents usually find out the need for an EIA study only when it has become a hindrance to project implementation, there is need to communicate the need for EIA within the government structures such that from any government office a proponent is informed on the need for EIA compliance at an early stage. Early knowledge of the EIA process allows the proponents to prepare for it so that the EIA process is not treated as an inconvenience to be rushed through for compliance sake. Given that most EIA reports relate to mining the Ministry of Mining and Mining Development could be more actively involved in EIA awareness-raising to proponents. In addition, the EIA process needs to be quickened so that it is not viewed as a bottleneck to development. This can be achieved by setting specific duration for each of the steps of the EIA process until certification.

Apart from awareness raising and enforcement, EMA needs to try other measures of promoting compliance such as use of economic incentives and disincentives. These most likely require fewer resources to implement than awareness raising and especially enforcement.

There is need to raise the entry barriers to EIA practice in order to eliminate unqualified and inexperienced consultants. This can be done in many ways including stricter and more stringent vetting of consultants before registration, enforcing stricter standards of EIA report quality and limiting the number of EIA consulting companies to ensure that consultants are full-time, specialise and hence more committed to professional EIA practice.

EMA needs strong capacity building to ensure that compliance monitoring and enforcement are more effectively 
practiced. Capacity building should incorporate increasing the number of staff, engaging and retaining well qualified staff, provision of equipment for measuring environmental indicator parameters, transport and managerial competency.

A full-scale national evaluation of the EIA system is long overdue since this is now 20 years since the EIA policy was formulated. There has not been a deliberate forum of multi-stakeholder contribution to the improvement of the EIA system.

\section{References}

Ahmad, B., \& Wood, C. M. (2002). Environmental impact assessment in Egypt, Turkey and Tunisia. Environmental Impact Assessment Review, 22, 213-234.

Badr, E. A. (2009, September). Evaluation of the environmental impact assessment system in Egypt. Impact Assessment and Project Appraisal, 27, 193-203.

Betey, C. B., \& Godfred, E. (2013). Environmental Impact Assessment and Sustainable Development in Africa : A Critical Review. Environment and Natural Resources, 3(2), 37-51.

Cashmore, M., Gwilliam, R., Morgan, R., Cobb, D., \& Bond, A. (2004). Effectiveness of EIA - The interminable issue of effectiveness: impact assessment theory. Impact Assessment and Project Appraisal, 22(4), 295-310.

El-Fadel, M., \& El-Fadel, K. (2004). Comparative Assessment of EIA Systems in MENA countries: Challenges and prospects. Environmental Impact Assessment Review, 24, 553-593.

Environmental Management Agency. (2010). Annual Report 2009. Harare: Ministry of Environment and Tourism.

Environmental Management Agency. (2011). Annual Report 2010. Harare: Ministry of Environment and Tourism.

International Cooperation Bureau. (2009). ODA Evaluation Guidelines. Tokyo: ODA Evaluation Division, Ministry of Foreign Affairs of Japan.

Kahangirwe, P. (2011, March). Evaluation of Environmental Impact Assessment (EIA) Practice in Western Uganda. Impact Assessment and Project Appraisal, 29, 79-83.

Khadka, R. B., \& Khanal, A. B. (2008). Environmental management plan (EMP) for Melamchi water supply project, Nepal. Environmental Monitoring and Assessment, 146(1-3), 225-34. http://doi.org/10.1007/s10661-007-0074-8

Lee, N., Colley, R., Bonde J., \& Simpson J. (1999). Reviewing the Quality of Environmental Statements and Environmental Appraisals. Occasional Paper number 55. Manchester; Department of Planning and Landscape. University of Manchester.

Manyindo, J. (2002). Monitoring Compliance with EIA Recommendations in Uganda: Opportunities for Progress. Uganda Wildlife Society, Kampala, Uganda

Mhango, S. D. (2005). The quality of environmental impact assessment in Malawi: a retrospective analysis. Development Southern Africa, 22(3), 383-408. http://doi.org/10.1080/14797580500252837

Ministry of Environment and Tourism. (1997). Environmental Impact Assessment Guidelines. Harare: Government of Zimbabwe.

Ministry of Environment and Tourism. (1997). Environmental Impact Assessment Policy. Harare: Government of Zimbabwe.

Ministry of Environment and Tourism. (2002). Environmental Management Act (Chapter 20.27). Harare: Government of Zimbabwe.

Nadeem, O., \& Hameed, R. (2006). A Critical Review of the Adequacy of EIA. International Journal of Human and Social Sciences, 1(1), 54-61.

Pope, J., Bond, A., Morrison-saunders, A., \& Retief, F. (2013). Advancing the theory and practice of impact assessment: Setting the research agenda. Environmental Impact Assessment Review, 41, 1-9. http://doi.org/10.1016/j.eiar.2013.01.008

Ruffeis, D., \& Loiskandl, W. (2010, March). Evaluation of the environmental policy and impact assessment system in Ethiopia. Environmental Protection, 28, 29-40.

Talime, L. A. (2011). A Critical Review of the Quality of Environmental Impact Assessment Reports in Lesotho. 
(Unpublished master's thesis) University of Free State, South Africa.

Wood, C. (1999). Comparative Evaluation of Environmental Impact Assessment Systems. In J. Petts (Ed.), Handbook of Environmental Impact Assessment (Vol. 2, pp. 10-34). Oxford: Blackwell.

Wood, C. (2003). Environmental Impact Assessment in Developing Countries: An Overview. Conference on New Directions in Impact Assessment for Development- Methods and Practice. EIA Centre, School of Planning and Landscape, University of Manchester, UK.

\section{Copyrights}

Copyright for this article is retained by the author(s), with first publication rights granted to the journal.

This is an open-access article distributed under the terms and conditions of the Creative Commons Attribution license (http://creativecommons.org/licenses/by/4.0/). 